\title{
Research on the power dispatching and trading mechanism oriented to low-carbon economy
}

\author{
Rui $\mathrm{Ge}^{1, \mathrm{a}}$, Miao Li ${ }^{2, \mathrm{~b}}$, Qiangming Zhou ${ }^{2, \mathrm{c}}$, Xu Cheng ${ }^{2, \mathrm{~d}}$, Dunnan Liu ${ }^{3, \mathrm{e}^{*}}, \mathrm{Bin}^{\mathrm{CaO}}{ }^{2, \mathrm{f}}$, \\ Lizheng Shao ${ }^{2, g}$ \\ ${ }^{1}$ State Grid Corporation of China, Beijing, China \\ ${ }^{2}$ State Grid Hubei electric power company, Wuhan, Hubei province, China \\ ${ }^{3}$ North China Electric Power University, Beijing, China \\ e715437085@qq.com, liudunnan@163.com
}

Keywords: low-carbon economy, power dispatching, external cost

Abstract. In the era of low-carbon economy, the traditional electric power industry will be confronted with tremendous changes on its external environment and internal developing model. The electric power industry should also pay closer attention to low-carbon, energy-saving as well as the emission of the $\mathrm{CO}_{2}, \mathrm{SO}_{2}, \mathrm{NO}_{\mathrm{X}}$, and dust in the operation of power system, except of the safety and economy. In addition, technical characteristics and large-scale using of all kinds of energy-saving and low emission power which may have effects on the operation of power system should be analyzed. Furthermore, "The power dispatching and trading method oriented to low-carbon economy", which is more scientific and efficient, should be applied in the electric power industry. Power dispatching facing low-carbon economy is proposed and the objective function, constraint condition and transaction mechanism about the power dispatching are also studied in this paper.

\section{Introduction}

In the era of low-carbon economy, the traditional electric power industry will be confronted with tremendous changes on its external environment and internal developing model. On the one hand, the introduction of economic mechanism and control means such as emission trading mechanism and carbon trading mechanism will shape a new macroeconomic environment and politic environment. Thus, it will increase the cost of discharge and meanwhile it will bring mitigation benefits. On the other hand, emission reduction, the significant target of the power industry, will also be the main constraint on every links, making the power industry present obvious reduction characteristics and a new operation mode. And it will finally have a large influence on power system operation.

\section{Background of the power dispatching and trading oriented to low-carbon economy}

With the ceaseless development of low-carbon economy, efficient conservation energy and pollutant emission reduction are undoubtedly the key challenges that electric power dispatching and trading will face in the future. The power dispatching and trading oriented to low-carbon economy has huge improvement over the previous modes.Based on traditional modes which stress fairness and economy, it not only makes a deep analysis in low-carbon and energy-saving during generation of electrical energy but also considers the emission characteristics and reduction potential of $\mathrm{CO} 2, \mathrm{SO} 2, \mathrm{NOX}$ and dust. Furthermore, it ensures the maximization of social welfare after full consideration of the external cost of electricity.

The low-carbon power dispatching and trading include: low-carbon energy-saving and emission reduction dispatching and trading, low-carbon comprehensive efficiency dispatching and trading. The goal mode of the low-carbon power dispatching and trading is a higher level than the former. 


\section{The framework of power dispatching and trading model oriented to low-carbon economy}

The traditional decision-making model of the power dispatching and trading used to depend on the power generation curve of each power source. Therefore, this mode can meet some requirements such as technical characteristics of power supply, network transmission conditions, the system load demand and peak shaving. And it can make sure to minimize the total cost. But this traditional decision-making model will have a significant change under the power dispatching and trading model oriented to low-carbon economy. It can mainly summarized as the following three aspects, the decision-making model framework of power dispatching and trading oriented to low-carbon economy as shown in figure 1.

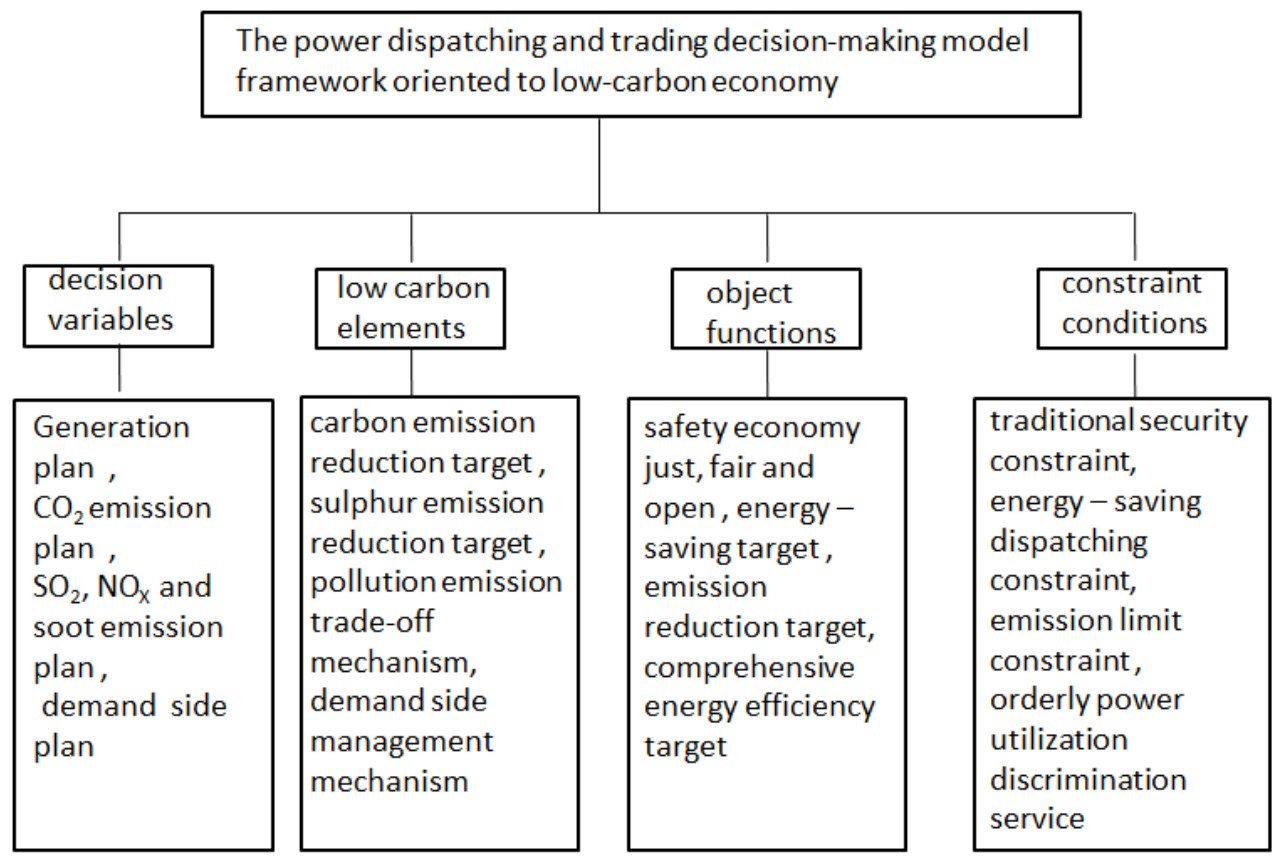

Fig. 1 The decision-making model framework of power dispatching and trading oriented to low-carbon economy

\section{The model of power dispatching and trading oriented to low-carbon economy}

\section{Object function}

The object function of the decision-making model is the lowest cost of power generation which includes units energy consumption cost and environmental cost caused by pollutant emission. The economic object function can be expressed as:

$$
\min \left(F_{p}=F_{u}+F_{s}+F_{c}+F_{n}+F_{y}\right)
$$

Where, $F_{p}$ is the total cost of power generation; $F_{u}$ is the cost of units energy consumption; $F_{s}, F_{c}, F_{n}$ and $\mathrm{F}_{\mathrm{y}}$ all mean environmental cost ,caused by the emission of $\mathrm{SO} 2, \mathrm{CO} 2, \mathrm{NOX}$ and dust respectively.

\section{Constraint condition}

(1)The constraints of load equalization

$$
\sum_{i=1}^{N} P_{i, t}=D_{t}+\mathrm{L}_{t}+\mathrm{T}_{t}
$$

Where, $D_{t}$ means the total load of the system at time $t ; L_{t}$ is the network loss at time $t ; T_{t}$ is the net output power of tieline at time $t$.

(2)Spinning reserve constraints

$$
\begin{gathered}
\sum_{i=1}^{N} \bar{r}_{i}(t) \geq \overline{p_{t}}(t) \\
\sum_{i=1}^{N} \underline{r}_{i}(t) \geq \underline{p_{t}}(t)
\end{gathered}
$$


Where, $\bar{r}_{i}(t)$ and $\underline{r}^{r_{i}}(t)$ are respectively up-regulated spinning reserve and down-regulated provided by unit i at time $\mathrm{t} ; \bar{p}_{t}(t)$ and $\frac{p}{t}^{(t)}$ mean demand for $\bar{r}_{i}(t)$ and $\underline{r}_{i}(t)$ separately.

(3)Unit operating constraints

$$
\begin{aligned}
& P_{i, t}+\bar{r}_{i}(t) \leq P_{i}^{\max } \\
& P_{i}^{\min } \leq P_{i, t}-\underline{r}_{i}(t) \\
& \left|P_{i, t}-P_{i, t-1}\right| \leq \Delta P_{i}
\end{aligned}
$$

Where, $P_{i}^{\max }$ is the maximum value of unit I output power and $P_{i}^{\min }$ is the minimum value; $\Delta P_{i}$ is the maximum value at the range of unit $i$ load change at single period.

(4)The constraints of grid security

$$
-P_{k, \max } \leq \sum_{i=1}^{M} l_{i, t} S_{i, k, t} \leq P_{\mathrm{k}, \max }
$$

Where, M means the number of joints; ${ }_{i, t}$ is the net input power of joint $\mathrm{i} ;{ }_{i, k, t}$ is the sensitivity of branch k power flow when joint $\mathrm{i}$ have the input power; $P_{\mathrm{k}, \max }$ is the maximum value of power for branch $\mathrm{k}$ power flow.

(5)The maximum and minimum of output power constraints

$$
P_{i}^{\min } \leq P_{i, t} \leq P_{i}^{\max }
$$

(6)Ramping rate constraints

$$
P_{R, i}^{D} \leq P_{i, t+1}-P_{i, t} \leq P_{R, i}^{U} \quad t=1,2 \ldots, T ; i=1,2 \ldots, N
$$
rate.

Where, $P_{R, k}^{D}$ is the limit of down ramping rate for unit i and $P_{R, k}^{U}$ means the limit of up ramping

(7)Hydropower generating constraints

For the hydropower station which has regulation ability, it always has the limit of daily total generating capacity.

$$
\sum_{t=1}^{T} P_{i, t} \leq P_{i, t}^{C a p}
$$

Where, $P_{i, t}$ means generating capacity at time $\mathrm{t},{ }^{\text {Cap }}$ is the limit of daily total generating capacity. (8)Wind power generating constraints

Wind can influence the output characteristics of wind generator because its motive power is the wind. Besides, the normal generating unit must adjust and compensate with the change of wind power for the purpose of keeping the system in balance when wind generators parallel in the power grid. Therefore, wind power output is no more than the absorptive capacity of power grid.

(9)Solar energy generating constraints

$$
P_{\mathrm{s}, t} \leq P_{\mathrm{s}, \max }
$$

Where, $P_{\mathrm{s}, t}$ is available power which generated by photovoltaic at time t; ${ }^{P_{\mathrm{s}, \max }}$ means photovoltaic power which can used by power grid.

(10)Nuclear power generating constraints

$$
P_{\mathrm{n}, t}=P_{\text {plan }}
$$

Nuclear generating power equivalent to the planned value due to it generally operate with base load and do not participate in peak shaving.

(11) $\mathrm{CO} 2$ emission constraints 


$$
\sum_{i=1}^{T} \sum_{i=1}^{N} E E_{i, t} \leq E E_{C O_{2}}
$$

Where, $E E_{i, t}$ is the amount of CO2 emission for unit i at time t; ${ }^{E \mathrm{CO}_{2}}$ is the maximum amount of $\mathrm{CO} 2$ emission in the decision-making period.

(12) $\mathrm{SO} 2$ emission constraints

$$
\sum_{t=1}^{T} \sum_{i=1}^{N} E_{i, t} \leq E_{S O_{2}}
$$

Where, ${ }_{i, t}$ is the amount of SO2 emission for unit $\mathrm{i}$ at time $\mathrm{t}$; ESO2 is the maximum amount of $\mathrm{SO} 2$ emission in the decision-making period.

(13)NOx emission constraints

$$
\sum_{t=1}^{T} \sum_{i=1}^{N} F_{i, t} \leq F_{N O_{x}}
$$

Where, $F_{i, t}$ is the amount of NOx emission for unit i at time $\mathrm{t} ; F_{N O_{x}}$ is the maximum amount of NOx emission in the decision-making period.

(14)Soot emission constraints

$$
\sum_{t=1}^{T} \sum_{i=1}^{N} G_{i, t} \leq G_{P M}
$$

Where, ${ }^{G_{i, t}}$ means the amount of soot emission for unit i at time t; $G_{P M}$ is the maximum amount of soot emission in the decision-making period.

(15)Energy - saving constraints

$$
\sum_{i=1}^{T} \sum_{i=1}^{N} H_{i, t} \leq H_{\max }
$$

Where, $H_{i, t}$ is the amount of coal consumption for unit i at time $\mathrm{t} ;{ }_{\max }$ is the maximum amount of coal consumption in the decision-making period.

\section{Summary}

In the era of low-carbon economy, the electric power industry should not only emphasizes the generating cost but also gives consideration to the cost of pollutant emission. The power dispatching oriented to low-carbon economy, proposed in this paper, aims to optimize the generating cost and cover the generating constraints of each clean power supply. Furthermore, there is a power dispatching and trading decision-making model in this paper which can contribute to save energy and reduce emission for the electric power industry.

\section{Acknowledgements}

This work was financially supported by the National Natural Science Foundation of China (71401055).

\section{References}

[1]Daniel KIRSCHEN, CHEN Qixin, KANG Chongqing, XIA Qing, Daniel KIRSCHEN. Mechanism and Modelling Approach to Low-carbon Power Dispatch. Automation of electric Power System, 2000,34(12), 18-23.

[2] Abido M A. Multi objective evolutionary algorithms. Electric Power Dispatch Problem[J]. IEEE Trans on Evolutionary Computation, 2006,10(3):315-329. 